\title{
Breakthrough Seizure Secondary to Hypocalcaemia in an Adolescent with Chronic Kidney Failure: A Case Report
}

\author{
Yeevon Poh* \\ School of Pharmacy, International Medical University, Malaysia
}

Submission: December 04, 2018; Published: December 17, 2018

*Corresponding author: Yeevon Poh, School of Pharmacy, International Medical University, Bukit Jalil, Kuala Lumpur, Malaysia

Abstract

Introduction: Epilepsy is the third most common neurological disorder worldwide, following stroke and Alzheimer's disease. Generally, the recommended effective dose of anticonvulsants was enough in attaining seizure control in $70-80 \%$ of the patients. However, there are also occasions where patients who are on stable regimen of anticonvulsants associated with breakthrough seizure either induced directly by hypocalcaemia or resulting from chronic kidney failure induced hypocalcaemia. Current paper presents the therapeutic approach for breakthrough seizure secondary to hypocalcaemia in the case of an adolescent with chronic kidney failure.

Case narrative: An epileptic male adolescent was admitted due to fitting lasted for 1 minute, followed by postictal drowsiness. Laboratory tests revealed optimal therapeutic range of Sodium Valproate serum concentration, but low serum calcium level. Hence, calcium replacement therapy was given as the main management plan.

Discussion: It is recommended that hypocalcaemia with neurological manifestations, without the underlying cause, should be managed with parenteral calcium. In chronic kidney failure patient, oral calcium and vitamin D should be started as soon as practical and maintained even after discharged. Whereas, anticonvulsants should be reserved only for persistent seizure even after correction of calcium level.

Conclusion: The management of breakthrough seizure should be individualised depending on clinical data and general condition of the patients.

Keywords: Breakthrough seizure; Hypocalcaemia; Chronic kidney disease; End stage renal failure; Adolescent; Calcium replacement therapy

Abbreviation: CKD: Chronic Kidney Failure; GABA: G-Aminobutyric Acid; BMI: Body Mass index ESRF: End Stage Renal Failure; BUSE: Blood Urea Serum Electrolyte; ALP: Alkaline Phosphatase; ALT Alanine Amino Transferase

\section{Introduction}

Seizure is characterised by an abrupt intense electrical impulse outburst in the brain, which begins with a small number of neuron fire abnormalities, followed by the breakdown of normal membrane conductance's and inhibitory synaptic currents [1]. The excitability is then spread locally (focal seizure) or more widely (generalised seizure) [1,2]. Whereas for epilepsy, it is considered only when involving synchronisation of excessive neuronal firing [1-3]. A basic assumption in epilepsy research proposed that the chronic recurrent paroxysmal changes of neuronal activity are generally arisen from an imbalance between g-aminobutyric acid (GABA)-mediated inhibitory and glutamate-medicated excitatory neurotransmission in favour at the latter. ${ }^{[3,4]}$ Therefore, most of antiepileptic drugs work by hindering the metabolism of GABA or exhibiting GABA mimetic effect $[1,4]$. However, there are still chances where epileptic patient exhibits seizure activity despite, he/she is on a stable regimen of antiepileptic drugs.
This phenomenon is typically defined as breakthrough seizure. It is shown to frequently exhibit in patients with predisposing endocrinological abnormalities or renal insufficiency with overall poor calcium homeostasis [5-7].

Globally, an estimated 50 million people are diagnosed with epilepsy, making it one of the most common neurological diseases worldwide and $80 \%$ of them live in developing countries including Malaysia [8]. However, the understanding and attitudes towards epilepsy in Malaysia are still unsatisfied, whereby it is often recognised as condition due to mythic causes, such as demonic possession [9]. Generally, it is estimated that epilepsy occurs in up to about $1 \%$ of the total Malaysia population [10]. The current paper focuses on the treatment approach for the case of a Malaysian adolescent presented with breakthrough seizures secondary to hypocalcaemia. 


\section{Case Narrative}

A 13-year-old Malay male patient (height $/$ weight = $155 \mathrm{~cm} / 45 \mathrm{~kg}$, calculated $\left.\mathrm{BMI}=18.7 \mathrm{~kg} / \mathrm{m}^{2}\right)$, with 3 years' history of peritoneal dialysis presented following a sudden episode of fitting during sleep. He was referred to current hospital due to uncontrolled hypertension. The episode of breakthrough seizures lasted for $1 \mathrm{~min}$, followed by postictal drowsiness. During the seizure, there was loss of consciousness with consecutive muscular contractions and relaxation. However, no trauma such as a fall or impact took place. Before admission, he was on Tab. Sodium Valproate 200mg TDS for epilepsy and claimed that he was compliant with the medication. Besides, he gave a history of pelvic fracture two years ago due to seizure and orthopaedic follow up was scheduled on next week.

He had been diagnosed with end-stage renal failure (ESRF) and hypertension since 2015. Tab Calcium Carbonate 2g TDS and Tab. Zincofer (contains ferrous fumarate $300 \mathrm{mg}$, folic acid $1 \mathrm{mg}$, vitamin B6 1.5mg, vitamin B12 5mcg, ascorbic acid $75 \mathrm{mg}$, zinc sulphate monohydrate $55 \mathrm{mg}$ ) I/I OD were given to the patient as the management of chronic kidney disease (CKD), whereas Tab. Prazosin 2mg TDS, Tab.Telmisartan 80mg OD, Tab.Perindopril 8mg OD and Tab.Bisoprolol 10mg OD were prescribed for the management of hypertension. He claimed that he generally compliant with the medications, except Tab.Calcium Carbonate and Tab.Zincofer as he erroneously thought that they are merely supplements. Other than that, he does not take any supplements or herbal products. His clinical history was negative in terms of steroid use, alcohol and tobacco consumption. He does not have any known drug allergy and family history of related illness [11] (Table 1).

Table 1: Table shown patient's vital signs on admission to emergency department. Tab. Captopril 25mg.

\begin{tabular}{|c|c|}
\hline Vital Signs & Readings \\
\hline Blood Pressure & $174 / 104 \mathrm{mmHg}$ \\
\hline Temperature & $37.3^{\circ} \mathrm{C}$ \\
\hline Heart Rate & 74 beats $/ \mathrm{min}$ \\
\hline Respiratory Rate & 20 breaths $/ \mathrm{min}$ \\
\hline Oxygen Saturation & $99 \%$ on room air \\
\hline Pain Score & $0 / 10$ \\
\hline
\end{tabular}

Urea level, serum creatinine and creatinine clearance of the patient was out of range because he is diagnosed with end-stage renal failure (Stage 5 of Chronic Kidney Disease). Decreased renal phosphate excretion is commonly reported in patient with severe kidney failure. By precipitating calcium, decreasing vitamin D production, and interfering with PTH-mediated bone resorption, hyperphosphatemia can cause hypocalcaemia. That why, oral calcium, which acts as the phosphate binder is often prescribed to patient with chronic kidney disease $[12,13]$ (Table 2).

Table 2: Table shown patient's Blood Urea Serum Electrolyte (BUSE) and renal profile on admission.

\begin{tabular}{|c|c|c|c|c|c|c|}
\hline \multirow{2}{*}{} & \multirow{2}{*}{ Normal Range } & \multicolumn{4}{|c|}{ Actual Value } \\
\cline { 2 - 6 } & & Day 1 & Day 2 & Day 3 & Day 4 & Day 5 \\
\hline $\mathrm{Urea}$ & $1.7-8.3 \mathrm{mmol} / \mathrm{L}$ & 20.1 & & 18.9 & 18.2 \\
\hline $\mathrm{Na}$ & $135-145 \mathrm{mmol} / \mathrm{L}$ & 139 & & 143 & 143 \\
\hline $\mathrm{K}$ & $3.5-5.0 \mathrm{mmol} / \mathrm{L}$ & 3.9 & & 3.9 & 3.9 \\
\hline $\mathrm{Cl}$ & $96-106 \mathrm{mmol} / \mathrm{L}$ & 93 & & 97 & 98 \\
\hline $\mathrm{Ca}$ & $2.1-2.6 \mathrm{mmol} / \mathrm{L}$ & 1.39 & 1.35 & 1.40 & 1.76 & 1.79 \\
\hline $\mathrm{Mg}$ & $0.7-1.3 \mathrm{mmol} / \mathrm{L}$ & 0.96 & & 0.91 & 0.92 \\
\hline $\mathrm{PO4}-$ & $0.8-1.45 \mathrm{mmol} / \mathrm{L}$ & 1.89 & & 1.99 & & 1.99 \\
\hline $\mathrm{SrCr}$ & $50-110 \mathrm{umol} / \mathrm{L}$ & 1492 & & 1446 & & 1450 \\
\hline $\mathrm{ClCr}$ & $75-125 \mathrm{~mL} / \mathrm{min}$ & 4.7 & & 4.85 & & 4.84 \\
\hline
\end{tabular}

Table 3: Table shown patient's liver profile on admission.

\begin{tabular}{|c|c|c|}
\hline & Normal Range & Actual Value \\
\hline Albumin & $35-50 \mathrm{~g} / \mathrm{L}$ & 30 \\
\hline T. Protein & $66-87 \mathrm{~g} / \mathrm{L}$ & 56 \\
\hline ALP & $53-141 \mathrm{u} / \mathrm{L}$ & 444 \\
\hline ALT & $<32 \mathrm{u} / \mathrm{L}$ & 37 \\
\hline
\end{tabular}

Higher readings of Alkaline Phosphatase (ALP), alanine aminotransferase (ALT) and low albumin levels suggesting abnormality of liver tissue, liver disease or bile duct blockages [14] (Table 3). Therefore, further investigation should be recommended to the patient to assess the risk of liver impairment. Following admission to previous hospital, patient's blood was sampled for Sodium Valproate serum concentration monitoring and optimal therapeutic range of $51 \mathrm{mcg} / \mathrm{ml}$ Sodium Valproate serum concentration (Target range: $50-100 \mathrm{mcg} / \mathrm{ml}$ ) [11] was reported. Considering that his clinical response was satisfied with minimal risk of adverse drug reaction, he was continued with Tab. Sodium Valproate 200mg TDS. Whereas, his Blood Urea Serum Electrolyte (BUSE) profile demonstrated serum total calcium level of 1.32mmol/L (normal: 2.1-2.6 mmol/L). Thus, IV Calcium Gluconate $10 \%$ in $10 \mathrm{~mL}$ was given as initial management of breakthrough seizure secondary to hypocalcaemia.

However, only slight increment of $0.07 \mathrm{mmol} / \mathrm{L}$ in serum calcium level was noted following admission to current hospital. As the level dropped on the next morning, patient was started on IV Calcium Gluconate 4 amp in 100cc normal saline over 4 hours and Tab.Calcium Carbonate 3g TDS. IV Calcium Gluconate $1 \mathrm{amp}$ in $100 \mathrm{cc}$ NS was administered 5 hours later due to insufficient increment of serum calcium level. On the following day of 
admission, patient was continued with oral calcium and started on vitamin D therapy. As a result, patient appeared fit free and his neurological assessment reviewed normal, despite the serum calcium level remained out of range $(1.79 \mathrm{mmol} / \mathrm{L}$ on the day of discharge). He was discharged on the $6^{\text {th }}$ day of admission and,

Table 4: Table shown list of patient's discharge medications.

\begin{tabular}{|c|c|c|c|c|c|}
\hline No. & Dosage & Medication & Dose & Frequency & Indication \\
\hline 1. & Tab. & Sodium Valproate & $200 \mathrm{mg}$ & TDS & Seizure \\
\hline 2. & Tab. & Diazepam & $5 \mathrm{mg}$ & PRN & Seizure \\
\hline 3. & Tab. & Calcium Carbonate & $3 g$ & TDS & $\begin{array}{l}\text { Phosphate Binder, } \\
\text { Hypocalcaemia }\end{array}$ \\
\hline 4. & Cap. & Alfacalcidol & $0.25 \mathrm{mcg}$ & $\mathrm{BD}$ & Hypocalcaemia \\
\hline 5. & Tab. & Prazosin & $5 \mathrm{mg}$ & TDS & Hypertension \\
\hline 6. & Tab. & Perindopril & $8 \mathrm{mg}$ & ON & Hypertension \\
\hline 7. & Tab. & Bisoprolol & $10 \mathrm{mg}$ & $\mathrm{BD}$ & Hypertension \\
\hline 8. & Tab. & Felodipine & $10 \mathrm{mg}$ & $\mathrm{BD}$ & Hypertension \\
\hline 9. & Tab. & Methyldopa & $250 \mathrm{mg}$ & $\mathrm{BD}$ & Hypertension \\
\hline 10. & Tab. & Telmisartan & $80 \mathrm{mg}$ & ON & Hypertension \\
\hline 11. & Tab. & Zincofer & $1 / 1$ & OD & Anaemia \\
\hline
\end{tabular}

\section{Total Serum Calcium Level}

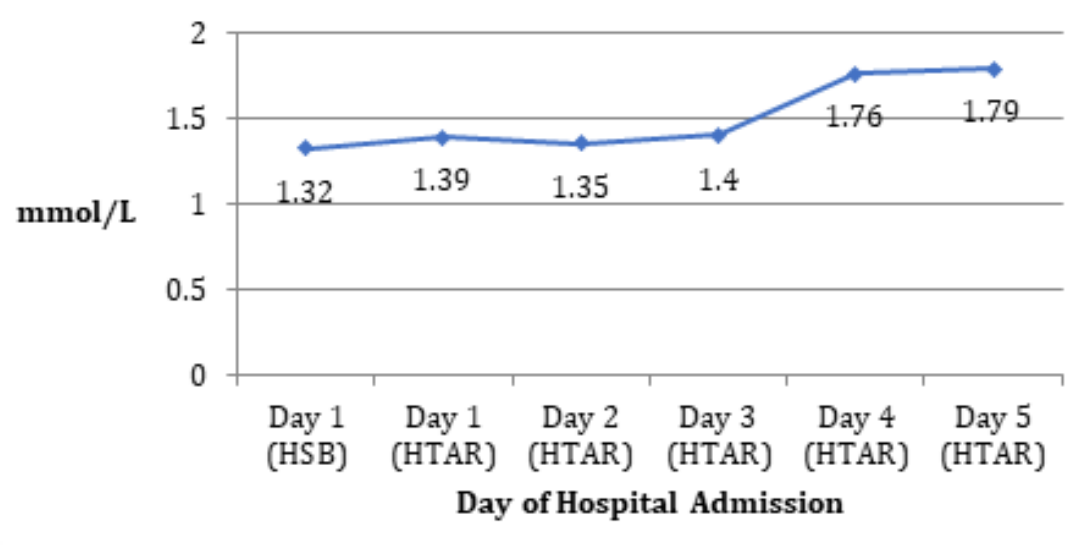

Figure 1: Figure shown patient's total serum calcium level. HSB denotes previous hospital, HTAR denotes current hospital.

\section{Discussion}

Hypocalcemia is a condition arises by reducing serum ionised calcium concentration (normal: 2.1-2.6 mmol/L) [15]. The common hypocalcaemia neurological manifestations include delirium, tetany and seizure, indicating a role of hypocalcaemia in causing neurological abnormalities [5,15,16]. Studies suggested that from inducing neurotransmitters release, to the electrical mechanical coupling in the myocyte, almost every step in the neuromuscular function is predicated on calcium $[5,17]$. Therefore, management in cases of hypocalcaemia seizures has universally comprised of calcium replacement with or without anticonvulsants [5-7,16,18,19].

Generally, an acute symptomatic hypocalcaemia case involving cardiovascular and neuromuscular systems (paraesthesia's, irritability, seizures, hypotension, and myocardial depression etc) signals the requirement of intravenous calcium $[15,16,20]$. Most reviews advocate the use of IV Calcium Gluconate $10 \%$ in $10 \mathrm{~mL}$ over 10 minutes as initial management $[11,15,20]$. Due to lower risk of extravasation induced tissue necrosis, it is preferred to Calcium Chloride [21]. Even so, it is advised that the administer should be done slowly with approximately $1.5 \mathrm{~mL}$ Calcium Gluconate $10 \%$ per minute to avoid prompt increases in the serum calcium [11]. If patient is still symptomatic or desired serum calcium level is yet to achieve, a chronic intravenous drip can then be started. Generally, continuous infusion of Calcium Gluconate 200 to $800 \mathrm{mg} / \mathrm{kg} /$ day is suggested. The infusion rate should be guided by signs, symptoms and calcium measurements every 1-2 hours. Nevertheless, throughout the therapy, an ongoing electrocardiography monitoring is crucial to observe patient's clinical response $[5,11,15,20]$. 
In the case of persistent hypocalcaemia despite chronic intravenous calcium therapy was given, treatment should be directed to the underlying factor as it can attenuate the therapeutic effect of calcium and vitamin D [19]. The differential diagnosis of hypocalcaemia in adolescence includes vitamin D deficiency, malabsorption, hypomagnesaemia and hypoparathyroidism.
Therefore, once hypocalcaemia is found, it is recommended to carry out additional evaluations on parathyroid hormone, magnesium, vitamin D 25-hydroxy and 1,25-dihydroxy levels [21]. However, in the view of patient's minimal responsive towards calcium therapy, no further investigation was performed throughout his hospital stay.

Table 5: Table shown the recommended dose of oral calcium for adolescents with Chronic Kidney Disease [11,23].

\begin{tabular}{|c|c|c|}
\hline Oral Calcium & $\begin{array}{c}\text { Percentage of } \\
\text { Elemental Calcium }\end{array}$ & Daily Dosing \\
\hline Tab. Calcium Carbonate & $40 \%$ & $\begin{array}{c}1300 \text { mg of elemental } \\
\text { calcium is recommended } \\
\text { for children of } 9-18 y e a r s .\end{array}$ \\
\hline Tab. Calcium Lactate & $13 \%$ & \\
\hline
\end{tabular}

Oral calcium and a rapidly acting preparation of vitamin D should be started as soon as practical during the admission [15]. They are also used in chronic calcium therapy to keep the patient free of symptoms and to maintain serum calcium at the normal range. Considering that the pathogenesis of CKD induced hypocalcaemia is typically recognised as increasing serum phosphorus and decreasing in renal production of 1,25-dihydroxycholecalciferol, the patient was discharged with Tab. Calcium Carbonate, a phosphate binder and Cap. Alfacalcidol, an active form of vitamin $\mathrm{D}[15,22]$. Besides, it is also recommended that in order to achieve an optimal therapy, patient should hold vitamin D dose constant and adjust the dose of Calcium Carbonate when signs, symptoms and measurements of calcium so dictate $[15,22,23]$ (Table 5).

The usefulness of standard anticonvulsants, in this case, is debatable. Certainly, in the cases where seizures persist even after correction of calcium levels, initiation of anticonvulsant is preferable $[16,18,24]$. Diazepam is the common medication indicated for breakthrough seizures. Review suggested that despite the metabolites of diazepam are active and long lasting, it is rarely a problem in children [24]. Undoubtedly, intravenous Diazepam $(0.2 \mathrm{mg} / \mathrm{kg}$, maximum dose: $20 \mathrm{mg}$ ) [11] is considered as the preferred administration route during a seizure [24] (Table 6). Table 6: Table shown the recommended form of vitamin $D$ for adolescents with Chronic Kidney Disease [11,23].

\begin{tabular}{|c|c|c|}
\hline Vitamin D & Daily Dosing & Administration \\
\hline Calcitriol & $\begin{array}{c}0.25 \mathrm{mcg} \text { daily, } \\
\text { may increase up to } \\
0.5-1.0 \mathrm{mcg} \text { daily }\end{array}$ & $\begin{array}{c}\text { May take with } \\
\text { or without meal }\end{array}$ \\
\hline Alfacalcidol & $1 \mathrm{mcg} /$ dialysis & Take with meal \\
\hline
\end{tabular}

\section{Conclusion}

In short, the current paper illustrates that the case of breakthrough seizure secondary to hypocalcaemia should be carefully evaluated, both at the presentation and after patient recovers from the postictal stage. This is because the underlying cause of hypocalcaemia should be ruled out in order to ensure optimal clinical response towards calcium therapy. Besides, it is also recommended that epileptic adolescent with CKD should be periodically followed for signs and symptoms of hypocalcaemia and vitamin D deficiency after discharged from the hospital. By practice this, it is believed that episode of breakthrough seizure can be prevented with a reasonable degree of success, provided that they fully comply with their assigned drug regimen.

\section{Patient Consent}

Obtained

\section{References}

1. Barbara G, Terry L, Joseph T (2017) Pharmacotherapy Handbook. (10 Edition), Mc Graw Hill Education,USA, pp. 816-825.

2. Shellhaas RA, Soaita AI, Clancy RR (2007) Sensitivity of amplitudeintegrated electroencephalography for neonatal seizure detection. Pediatrics 120(4): 770-777.

3. Jiruska P, De Curtis M, Jefferys JG, Schevon CA, Schiff SJ, et al. (2013) Synchronization and desynchronization in epilepsy: controversies and hypotheses. The Journal of physiology 591(4): 787-797.

4. Meurs A, Clinckers R, Ebinger G, Michotte Y, Smolders I (2008) Seizure activity and changes in hippocampal extracellular glutamate, GABA, dopamine and serotonin. Epilepsy research 78(1): 50-59.

5. El Asri AC, Akhaddar A, Baallal H, El Mostarchid B, Boulahroud O, et al. (2012) Hypocalcemic seizure in adult: Rare cause of lumbar fracture. Clinical neurology and neurosurgery 114(6): 738-740.

6. Tsai PL, Lian LM, Chen WH (2009) Hypocalcemic seizure mistaken for idiopathic epilepsy in two cases of DiGeorge syndrome (chromosome 22q11 deletion syndrome). Acta Neurologica Taiwanica 18(4): 272275.

7. Kinoshita H, Kokudo T, Ide T, Kondo Y, Mori T, et al. (2010) A patient with DiGeorge syndrome with spina bifida and sacral myelomeningocele, who developed both hypocalcemia-induced seizure and epilepsy. Seizure 19(5): 303-305.

8. Improving access to epilepsy care. World Health Organization.

9. Ab Rahman AF (2005) Awareness and knowledge of epilepsy among students in a Malaysian university. Seizure: European Journal of Epilepsy 14(8): 593-596.

10. Yayasan Sime Darby (2014) Epilepsy Awareness and Treatment Program with Sime Darby Medical Centre Subang Jaya.

11. Hudson, Ohio (2017) Drug information handbook. (25 $5^{\text {th }}$ Edition) Lexicomp,USA, pp. 286-292. 
12. (2002) National Kidney Foundation. KDOQI Clinical Practice Guidelines for Chronic Kidney Disease: Evaluation, Classification and Stratification. AM J Kidney Dis 39: S1-S000.

13. (2017) Hyperphosphatemia: Practice Essentials, Background, Pathophysiology. Emedicine.

14. Liver problems - Diagnosis and treatment - Mayo Clinic.

15. Shoback D, Madhu N Rao (2018) Hypocalcemia Management

16. Han P, Trinidad BJ, Shi J (2015) Hypocalcemia-induced seizure: demystifying the calcium paradox. ASN neuro 7(2).

17. Gehlert S, Bloch W, Suhr F (2015) $\mathrm{Ca}^{2+}$-dependent regulations and signaling in skeletal muscle: from electro-mechanical coupling to adaptation. International journal of molecular sciences 16(1): 1066 1095.

18. Gkampeta A, Kouma E, Touliopoulou A, Aggelopoulos E, Vourti E (2016) Afebrile seizures as initial symptom of hypocalcemia secondary to hypoparathyroidism. Journal of neurosciences in rural practice 7(5) 117-119.
19. Robert B, Schonberger (2018) Fluid, Electrolyte, and Acid-Base Disorders. Stoelting's Anesthesia and Co-Existing Disease. Chapter 21 pp. 407-424.

20. Hassan Z, Smith N (2017) Hypocalcaemia. Medicine 45(9): 555-559.

21. Schnadower D, Agarwal C, Oberfield SE, Fennoy I, Pusic M (2006) Hypocalcemic seizures and secondary bilateral femoral fractures in an adolescent with primary vitamin D deficiency. Pediatrics 118(5): 2226-2230.

22. Messa P (2012) The ups and downs of dialysate calcium concentration in haemodialysis patients. Nephrology Dialysis Transplantation 28(1): 3-7.

23. Goltzman D, J Rosen C, E Mudler J (2018) Treatment of hypocalcemia. Uptodate.

24. Richard H, Helen D (2018) Neurologic Symptoms. Textbook of Interdisciplinary Pediatric Palliative Care. Chaper 27, pp. 239-250.

\section{Your next submission with Juniper Publishers will reach you the below assets}

- Quality Editorial service

- Swift Peer Review

- Reprints availability

- E-prints Service

- Manuscript Podcast for convenient understanding

- Global attainment for your research

- Manuscript accessibility in different formats (Pdf, E-pub, Full Text, Audio)

- Unceasing customer service

Track the below URL for one-step submission https://juniperpublishers.com/online-submission.php 